\title{
Diffusion Studies in Magnetron Sputter Deposited Silicon Nitride Films
}

\author{
J Kulczyk-Malecka $^{1}$, PJ Kelly $^{1 *}$, G West ${ }^{1}$, GCB Clarke ${ }^{2}$, JA Ridealgh $^{2}$ \\ ${ }^{1}$ Surface Engineering Group, Manchester Metropolitan University, Manchester, M1 5GD, UK \\ ${ }^{2}$ Pilkington Technology Management Ltd., part of NSG group, Lathom, L40 5UF, UK
}

"Tel: +441612474643

peter.kelly@mmu.ac.uk

\begin{abstract}
In this work, silicon nitride coatings were deposited by magnetron sputtering onto float glass substrates and post-deposition annealed at $650^{\circ} \mathrm{C}$ for 5 minutes. The structures and compositions of the coatings were investigated by X-ray diffraction, X-ray reflectometry, scanning electron microscopy and energy dispersive X-ray spectroscopy. Samples were then over-coated with silver and subjected to a second annealing process to initiate the diffusion of silver through the adjacent coating layers. Additional silicon nitride coatings were then deposited on selected samples to produce $\mathrm{Si}_{3} \mathrm{~N}_{4} / \mathrm{Ag} / \mathrm{Si}_{3} \mathrm{~N}_{4} /$ glass stacks, which were annealed at temperatures in the range $100-600^{\circ} \mathrm{C}$. Ag and $\mathrm{Na}$ diffusion coefficients were then calculated from compositional profiles obtained from time of flight secondary ion mass spectrometry analysis. The coatings deposited in this study were found to have stoichiometric $\mathrm{Si}_{3} \mathrm{~N}_{4}$ compositions and were amorphous after annealing. The diffusion rate of silver through these coatings was found to depend on annealing temperature and coating density and roughness, which in turn can be related to the deposition conditions.
\end{abstract}

\section{Key words:}

Thin films; Diffusion; Magnetron sputtering; Silicon nitride 


\section{Introduction}

Silicon nitride $\left(\mathrm{Si}_{3} \mathrm{~N}_{4}\right)$ is a covalent material which has high oxidation and corrosion resistance, high thermal stability, low mass density, high dielectric constant and high hardness. These properties make it a very desirable coating material in many fields. It is widely used as an insulator between conductors and as a diffusion barrier for metals, water and oxygen, even at very high temperatures [1-3]. The transparency of silicon nitride over a wide spectral range from near-ultraviolet (UV) to the infrared (IR) region, along with its passivating properties makes it suitable for many optical applications [2]. One such application is in low emissivity (Low-E) coatings, which are applied to large area architectural glazing to reduce heat losses from buildings. They combine high visible transparency with high reflectance in the far-infrared region. To achieve this combination of properties, Low-E coatings generally consist of dielectric/silver/dielectric multi-layer systems or stacks, where the thin $(\sim 10 \mathrm{~nm})$ silver layer reflects long wavelength IR back into the building and the dielectric layers both protect the silver and act as anti-reflectance layers. In addition to $\mathrm{Si}_{3} \mathrm{~N}_{4}, \mathrm{TiO}_{2}, \mathrm{SnO}_{2}$ or $\mathrm{ZnO}$, are all widely used for the dielectric layers and all the layers are usually deposited by magnetron sputtering [4-6].

The market for Low-E coatings has grown considerably in recent years due to environmental legislation and increased energy costs. To further expand the market, the next generation of Low-E coatings are increasingly being deposited onto toughenable glass, which is postdeposition annealed at temperatures of up to $650^{\circ} \mathrm{C}$. However, under these conditions, silver atoms are highly mobile and can rapidly diffuse through the other constituent layers of the coating stack, which can have a detrimental impact on the performance of the coating. Furthermore, sodium atoms can also diffuse from the glass substrate into the coating stack. Although diffusion in bulk materials has been widely studied, the same cannot be said of diffusion in thin films. In polycrystalline films, diffusion occurs more rapidly than in bulk materials due to the higher degree of defects, such as vacancies or grain boundaries [7]. Also 
the mechanism of diffusion in thin films is different to that for bulk samples. In thin films, diffusion can occur through grains or along the grain boundaries, depending upon the microstructure of the film [8]. The aim of this project, therefore, was to carry out a detailed study of diffusion processes in $\mathrm{Si}_{3} \mathrm{~N}_{4} / \mathrm{Ag} / \mathrm{Si}_{3} \mathrm{~N}_{4} /$ glass coating systems deposited by magnetron sputtering techniques under industrially relevant conditions (i.e. using commercially available magnetron designs and power deliver modes). The first stage of the work was to investigate the structural properties of $\mathrm{Si}_{3} \mathrm{~N}_{4}$ coatings following an annealing process. Simple two layer $\mathrm{Ag} / \mathrm{Si}_{3} \mathrm{~N}_{4} /$ glass stacks were then investigated to gain a better understanding of the diffusion of silver and sodium through silicon nitride coatings. This allowed a model to be developed, which could then be applied to the more complicated triple layer $\mathrm{Si}_{3} \mathrm{~N}_{4} / \mathrm{Ag} / \mathrm{Si}_{3} \mathrm{~N}_{4} /$ glass stacks. In the triple layer system silver diffuses into both adjacent $\mathrm{Si}_{3} \mathrm{~N}_{4}$ layers, making this design is a good representation of multilayer systems in Low-E coatings deposited on an industrial scale. Time of flight secondary ion mass spectrometry (TOF-SIMS) was used to perform the depth profiling analysis, from which the diffusion coefficient values presented here were calculated.

The conventional technique to deposit silicon nitride is high temperature $\left(700-800^{\circ} \mathrm{C}\right) \mathrm{CVD}$, which enables the deposition of stoichiometric $\mathrm{Si}_{3} \mathrm{~N}_{4}$, but results in hydrogen contamination, due to the choice of precursors [3]. The hardness and optical properties of these films are influenced by the N/Si ratio in the film, the total hydrogen content and the bonding between silicon, nitrogen, and hydrogen. Such a high deposition temperature is undesirable and one of the advantages of depositing silicon nitride by reactive magnetron sputtering is the much lower deposition temperature $\left(<150^{\circ} \mathrm{C}\right)$ and the higher purity of the resulting coating, especially the lack of hydrogen contamination of the film surface [9].

\section{Experimental}

Silicon nitride films were reactively sputtered from a full face erosion (FFE, Gencoa Ltd.) planar magnetron using a $99.5 \%$ purity, $350 \mathrm{~mm} \times 125 \mathrm{~mm}$ silicon target bonded to a copper 
backing plate. The magnetron was driven by an Advanced Energy Pinnacle Plus power supply operating in pulsed DC mode at a frequency of $100 \mathrm{kHz}$ and $5.0 \mu \mathrm{sec}$ off time (i.e. $50 \%$ duty). In a FFE magnetron the central pole of the magnetic array can be rotated in use to sweep the plasma across the racetrack region. This reduces the effects of target poisoning (and therefore arcing) during reactive sputtering, leading to improved process stability and more uniform film deposition [10]. In these experiments, the magnets were continuously rotated at $250 \mathrm{rpm}$. Coatings were deposited onto $4 \mathrm{~mm}$ float glass at target powers in the range 150-300 W, with run times adjusted to give an estimated coating thickness of $80 \mathrm{~nm}$. The amount of argon and nitrogen gases introduced into the chamber during sputtering was controlled by MKS mass flow controllers, and varied from 9-11 SCCM of nitrogen, with an argon flow rate of 35 or 50 SCCM, for samples deposited of 300 and $150 \mathrm{~W}$ power, respectively. Coatings were produced using a range of operating pressures from 0.3-0.9 $\mathrm{Pa}$, which covers the range that might be used in an industrial process. The operating pressure was raised by closing the baffle over the diffusion pump to reduce the pumping speed in the chamber, and therefore, prevent excessive gas loads on the pumps.

The silicon nitride coatings were post-deposition annealed at $650^{\circ} \mathrm{C}$ for 5 minutes, which is the maximum temperature currently applied in industrial glass toughening processes. Samples were removed from the oven after 5 minutes and allowed to cool down in air before being characterised by various analytical techniques described below. The silicon nitride samples were then over-coated with silver, which was deposited by DC magnetron sputtering from a 99.95\% pure Ag target. Prior to deposition of the silver layer, the samples were 'dusted off' with clean air, but not otherwise cleaned. A standard planar $300 \mathrm{~mm} \times 100 \mathrm{~mm}$ unbalanced magnetron (Teer Coatings Ltd.) was driven by an Advanced Energy Pinnacle Plus power supply at a power of $100 \mathrm{~W}$. The thickness of the metal layer was about $100 \mathrm{~nm}$ in the $\mathrm{Ag} / \mathrm{Si}_{3} \mathrm{~N}_{4}$ stacks and about $10 \mathrm{~nm}$ in the $\mathrm{Si}_{3} \mathrm{~N}_{4} / \mathrm{Ag} / \mathrm{Si}_{3} \mathrm{~N}_{4}$ 'sandwich' stacks. 
All of the $\mathrm{Ag} / \mathrm{Si}_{3} \mathrm{~N}_{4}$ stacks were re-annealed at $250^{\circ} \mathrm{C}$ for 5 minutes to investigate the diffusion of silver and sodium through the silicon nitride coatings. Additionally sample 1 was also annealed at the temperature range $100-600^{\circ} \mathrm{C}$ for 5 minutes to investigate the Arrhenius temperature dependency of diffusion. Compositional depth profiles were measured using time of flight secondary ion mass spectrometry (ION TOF 5) with a $\mathrm{Bi}^{3+}$ analysis beam and a 1 $\mathrm{keV} \mathrm{Cs}^{+}$sputter beam; the methodology has been described elsewhere [11]. An additional 'standard' coating was prepared, based on the conditions for sample 1, which was not subjected to second annealing at $250^{\circ} \mathrm{C}$ after $\mathrm{Ag}$ deposition, but analysed by TOF-SIMS after spending approximately 24 hours at room temperature.

In the three layer stacks, both of the $\mathrm{Si}_{3} \mathrm{~N}_{4}$ layers were deposited under the conditions for sample 1, since this set of conditions were considered to be most representative of our standard operating conditions. The three layer stacks were deposited without breaking the vacuum using a rotatable substrate holder, which allowed the substrate to be positioned and held in front of the desired metal target prior to film deposition.

Following this, the three-layer $\mathrm{Si}_{3} \mathrm{~N}_{4} / \mathrm{Ag} / \mathrm{Si}_{3} \mathrm{~N}_{4}$ stacks were post-deposition annealed over the temperature range of $100-600^{\circ} \mathrm{C}$ for 5 minutes to investigate the Arrhenius temperature dependency of diffusion. The three-layer stacks represent similar coating compositions to Low-E designs, but lacking in the additional barrier coatings used in industry. This way it was possible to investigate silver diffusion through $\mathrm{Si}_{3} \mathrm{~N}_{4}$ at elevated temperatures and to compare Ag diffusion rates in other dielectric materials, such as $\mathrm{ZnO}$ or $\mathrm{TiO}_{2}$, which are described elsewhere [12], and to identify optimal layers that would have low optical adsorption, good mechanical durability and would serve as a barrier for silver diffusion. To simplify the diffusion profile, sodium diffusion was omitted in this part of study.

The deposition conditions for the silicon nitride samples are listed in Table 1. 
A wide range of analytical techniques were used to investigate the structure, morphology and composition of the silicon nitride coatings. Due to the limitations of certain techniques, additional samples were deposited under identical operating conditions, but for longer times to achieve a thickness of about $1 \mu \mathrm{m}$. EDX (Trident ${ }^{\mathrm{TM}}$ system) with $40 \mathrm{~mm}^{2}$ silicon drift detector and an ion beam energy of $8 \mathrm{keV}$ was used to determine the stoichiometry of the deposited materials. The coating thickness was measured by a Dektak® II stylus profilometer (Vecco Instruments Inc.). To investigate the crystallographic proprieties, coupled $\theta-2 \theta$ X-ray diffraction (XRD, $\mathrm{X}^{\prime}$ Celerator detector) scans were performed using $\mathrm{Ni}$-filtered $\mathrm{Cu} \mathrm{K} \alpha$ radiation at $0.154056 \mathrm{~nm}$, scanning the samples from 5 to 75 degrees $2 \theta$ for times from 30 minutes up to 5 hours. To determine the surface morphology, the dielectric coatings were examined by scanning electron microscopy (SEM, Zeiss Supra 40VP) operating at 1-3 kV. Additionally, X-ray reflectometry (XRR, PANalytical x'pert MRD) analysis was performed to investigate the density and roughness of the silicon nitride coatings. Reflectograms were obtained by scanning samples for 2 hours using a phase detector.

Silver and sodium diffusion rates were estimated by applying an analytical solution to Fick's second law and by solving the complementary error function equation using a macro programme available for commercial software packages [13-15]. The raw SIMS depth profiling data for silver, silicon nitride and silicon (detected from the glass when the substrate surface was reached) were firstly normalised to give relative concentration values from 0 to 1 . In this way the diffusion calculator converted intensity values measured in counts per second into relative silver concentrations. Sputter time was converted to depth (nm) using empirically measured thickness values of the dielectric coatings prior to the deposition of the silver layer as a reference value. The data were then fitted to the analytical solution of Fick's second law [13-14] curve using the diffusion calculator and the concentration of $\mathrm{Ag}$ was found by solving the complementary error function. 
The temperature dependence of the diffusion coefficient D is described by the Arrhenius equation:

$$
\mathrm{D}=\mathrm{D}_{0} \exp (-\mathrm{Q} / \mathrm{RT})
$$

where $\mathrm{D}_{0}$ is the temperature independent frequency factor, $\mathrm{Q}$ is the activation energy, $\mathrm{R}$ is the gas constant $(8.314 \mathrm{~J} / \mathrm{mol} \mathrm{K})$ and $\mathrm{T}$ is the temperature in Kelvin [16-17]. Plotting the Arrhenius equation should give a linear dependency between temperature and diffusivity, where the gradient equals $-\mathrm{Q} / \mathrm{R}$, and the intercept allows calculation of the frequency factor value $\left(\mathrm{D}_{0}\right)$.

\section{Results}

\subsection{Characterisation of silicon nitride coatings}

XRD analysis using both $\theta-2 \theta$ and glancing angle XRD (GAXRD) configuration showed no evidence of crystallinity for any of the samples listed in Table 1. Consequently the $\mathrm{Si}_{3} \mathrm{~N}_{4}$ coatings have been characterised as being amorphous. Löbl et al. have investigated silicon nitride coatings deposited by magnetron sputtering and determined that these films become crystalline after annealing at $825^{\circ} \mathrm{C}$. Below this temperature the coatings remained amorphous [18].

Stoichiometric silicon nitride- $\mathrm{Si}_{3} \mathrm{~N}_{4}$ consists of 42.9 at $\%$ of $\mathrm{Si}$ and 57.2 at $\%$ of N. Additional silicon nitride samples based on selected deposition conditions (samples 1 and 4) were deposited for a longer time to obtain thicknesses of approximately $1 \mu \mathrm{m}$, required to perform reliable EDX analysis. These samples show similar compositions of 43.7 at \% of $\mathrm{Si}$ and 56.3 at $\%$ of $\mathrm{N}$ in sample 1 , and 43.8 at $\%$ of $\mathrm{Si}$ and 56.2 at $\%$ of $\mathrm{N}$ in sample 4 , respectively. The amount of nitrogen in these samples is about $1-2 \%$ lower than for stoichiometric silicon nitride, which may be due to sample contamination. A small amount of oxygen was detected in the samples ( 0.7 and 1.8 at $\%$ in sample 1 and 4 , respectively), which probably came from background contamination in the chamber and is not considered significant. 
XRR measurements were performed under ambient conditions of temperature and pressure by directing an X-ray beam onto the specimen. The detector measures the intensity of the X-ray beam at an angle equal to the incident angle from the sample surface [19]. The theoretical density of silicon nitride is $3.4 \mathrm{~g} / \mathrm{cm}^{3}$, whereas measured values for the silicon nitride samples were found to be $3.0+/-0.1 \mathrm{~g} / \mathrm{cm}^{3}$ and post deposition annealing at $650^{\circ} \mathrm{C}$ for 5 minutes did not cause a significant difference in this value. Sample 5 showed the lowest density among analysed coatings of $2.7 \mathrm{~g} / \mathrm{cm}^{3}$, which may be related to the deposition conditions used (note - sample 5 at 2.7 is not in the range $3.0+/-0.1$ ).

XRR roughness was modelled from the rate of intensity drop-off that assumes a Gaussian distribution. The software assumes each layer has a constant density, variations from this decrease the accuracy and therefore make fitting more difficult. Roughness values were compared against standard roughness values obtained for float glass which is equal to $0.6 \mathrm{~nm}$. XRR roughness values varied from $1.0 \mathrm{~nm}$ obtained for sample 1, to $3.1 \mathrm{~nm}$ for sample 3 and no significant difference in surface roughness before and after annealing have been found. It suggests that the annealing conditions did not affect the surface roughness of the silicon nitride films investigated in this study. However, it is apparent that the highest roughness values were obtained for samples deposited under the highest operating pressure of $0.9 \mathrm{~Pa}$. Figure 1 shows the gradual increase of surface roughness values with operating pressure for these samples.

The density and roughness values measured by XRR are listed in Table 1.

SEM micrographs showing the surface morphology of $\mathrm{Si}_{3} \mathrm{~N}_{4}$ samples 1 and 4 are shown in Figure 2. The micrographs show dense, defect free surfaces, with varying degrees of texture or roughness noticeable on the sample surfaces. Sample 4 appears visibly rougher than sample 1 , confirming the influence of pressure on roughness. 


\subsection{Diffusion studies of $\mathrm{Ag} / \mathrm{Si}_{3} \mathrm{~N}_{4}$ stacks}

Figure 3 presents the TOF-SIMS depth profile of a 'standard' coating. Using the diffusion modelling program, the silver diffusion coefficient in the standard sample was calculated to be $1 \times 10^{-24} \mathrm{~m}^{2} / \mathrm{s}$ and the sodium diffusion coefficient is $1 \times 10^{-20} \mathrm{~m}^{2} / \mathrm{s}$. Figure 4 compares the sodium profiles obtained from the as-deposited sample 6 and annealed sample 3 (which were deposited under the same conditions). The level of $\mathrm{Na}$ in the heat treated samples is significantly higher than in the as-deposited sample. This suggests that during the first annealing process at $650^{\circ} \mathrm{C}$ sodium diffuses through almost the entire thickness of the silicon nitride coating. Whereas, the as-deposited sample shows sodium atoms present only close to the glass/silicon nitride coating interface.

Diffusion modelling showed that, after annealing, silver diffuses at similar rates in all the $\mathrm{Si}_{3} \mathrm{~N}_{4}$ samples prepared in this work. The diffusion rates are relatively low and stay in the range of $1 \times 10^{-20} \mathrm{~m}^{2} / \mathrm{s}$ to $5.5 \times 10^{-20} \mathrm{~m}^{2} / \mathrm{s}$ for all of the samples. Samples 3 and 4 show the highest diffusion rates of $5.5 \times 10^{-20} \mathrm{~m}^{2} / \mathrm{s}$.

More variation was observed for the diffusion rates of sodium through the silicon nitride samples. Diffusion coefficient values varied from $2.5 \times 10^{-20} \mathrm{~m}^{2} / \mathrm{s}$ in as-deposited sample 6 to $1.1 \times 10^{-18} \mathrm{~m}^{2} / \mathrm{s}$ in sample 5 . However, for the majority of samples the sodium diffusion rates were around $2 \times 10^{-19} \mathrm{~m}^{2} / \mathrm{s}$. The higher value for sample 5 is probably due to the fact that this coating was deposited under conditions likely to produce a lower density film, as confirmed by XRR.

Table 2 shows the diffusion coefficient values calculated for silver atoms diffusing through silicon nitride films annealed at the temperature range $100-600^{\circ} \mathrm{C}$ for 5 minutes. Figure 5 shows an Arrhenius plot of the logarithms of diffusion coefficients, D, as a function of the reciprocal temperature, $\mathrm{T}\left[\mathrm{K}^{-1}\right]$, and the activation energy and the frequency factor found from the plot were $38.1 \pm 1.9 \mathrm{~kJ} / \mathrm{mol}(\sim 0.3953 \mathrm{eV})$ and $3.97 \times 10^{-16} \mathrm{~m}^{2} / \mathrm{s}$, respectively. 


\subsection{Diffusion studies of multilayer $\mathrm{Si}_{3} \mathrm{~N}_{4} / \mathrm{Ag} / \mathrm{Si}_{3} \mathrm{~N}_{4}$ stacks}

The multilayer stacks described in the experimental section were investigated using the Arrhenius diffusion principle to find the temperature dependency of silver diffusion. Table 3 shows the diffusion coefficient values calculated for silver atoms moving through the adjacent silicon nitride layers in the stacks. Figure 6 shows an Arrhenius plot of the logarithms of diffusion coefficients, $\mathrm{D}$, as a function of the reciprocal temperature, $\mathrm{T}\left[\mathrm{K}^{-1}\right]$, and the activation energy and the frequency factor found from the plot were $34.3 \pm 1.7 \mathrm{~kJ} / \mathrm{mol}$ $(\sim 0.3554 \mathrm{eV})$ and $3.10 \times 10^{-17} \mathrm{~m}^{2} / \mathrm{s}$, respectively.

Silver profiles from the silicon nitride/silver/silicon nitride samples annealed over the temperature range $100-600^{\circ} \mathrm{C}$ are shown in Figure 7 . The area under curves represents raw TOF-SIMS counts, therefore results are not quantifiable and cannot be considered to represent Gaussian changes in peak intensity and broadening due to diffusion processes. Nevertheless, there is a general trend of reduction in peak height and increased peak broadening with annealing temperature, as silver diffused into both $\mathrm{Si}_{3} \mathrm{~N}_{4}$ layers. The influence of sodium diffusion has not been taken into consideration and it is currently under investigation.

\section{Discussion}

XRR results showed that the density of deposited coatings might be related to the deposition conditions used, as sample 5 was found to have the lowest density of $2.7 \mathrm{~g} / \mathrm{cm}^{3}$ among the samples investigated in this work. The relatively low power of $150 \mathrm{~W}$ used for this sample may have influenced the film structure. Operating a magnetron at low power usually means the discharge voltage is also low, leading to a lower ion current and lower ion energies incident at the substrate, limiting densification of the growing film by ion bombardment. As densification occurs by surface diffusion processes, it is reasonable to assume that adatoms having relatively low energy will not be as mobile as highly energetic adatoms. Sample 4 was also deposited at $150 \mathrm{~W}$, but at a lower pressure than sample 5 and its density is comparable 
with the remaining samples $\left(3.0 \mathrm{~g} / \mathrm{cm}^{3}\right)$. It is known that during the sputtering process the mean free path of the incident ions decreases when operating pressure increases, therefore the average ion energy is reduced through gas phase collisions. This implies that both low power and higher operating pressure may have been responsible for the creation of a more open film structure in the case of sample 5, compared to samples deposited at higher powers or lower pressures.

Moreover, XRR roughness analysis indicated that samples deposited at a lower average target power showed higher roughness values than those deposited at an average target power of 300 W. Li et al. reported that in $\mathrm{RF}$ magnetron sputtered $\mathrm{Si}_{3} \mathrm{~N}_{4}$ films, coating density increased with increasing nitrogen/argon flow ratio from 2.4 to $3.17 \mathrm{~g} / \mathrm{cm}^{3}$, but no correlation was observed between roughness and gas flow, as on average their roughness values were all around $0.6 \mathrm{~nm}[20] . \mathrm{Xu}$ et al. on the other hand showed that there is no correlation between substrate temperatures during film deposition and surface roughness or coating density. Values varied from 3.06 to $3.12 \mathrm{~g} / \mathrm{cm}^{3}$ for film density and from 0.44 to $0.5 \mathrm{~nm}$ for roughness obtained by XRR [21].

Diffusion studies of the $\mathrm{Ag} / \mathrm{Si}_{3} \mathrm{~N}_{4}$ films indicate that there is no apparent correlation between specific deposition conditions and the diffusion coefficient values obtained over the range investigated. Although the highest diffusion rates do seem to be associated with the conditions expected to produce the least dense coatings, as shown in the XRR results. For example, the sodium diffusion coefficient value for sample 5 was an order of magnitude higher than for the remaining samples annealed at $650^{\circ} \mathrm{C}$ and then $250^{\circ} \mathrm{C}$. Whilst this result might be due to the lower density of this coating no overall systematic trends of sodium diffusivity were identified. Furthermore, the differences in sodium diffusion rates are relatively small, which could be a result of the low magnitude of the diffusion rates involved and possible errors resulting from diffusion modelling programme limitations. 
As expected silver diffusivity follows the Arrhenius dependency in both two-layer $\mathrm{Ag} / \mathrm{Si}_{3} \mathrm{~N}_{4}$ and three-layer $\mathrm{Si}_{3} \mathrm{~N}_{4} / \mathrm{Ag} / \mathrm{Si}_{3} \mathrm{~N}_{4}$ stacks. The silver diffusivity increased significantly with increasing annealing temperatures, showing differences of three orders of magnitude between samples annealed at the lowest and the highest temperatures in these samples. The difference in the activation energy and frequency factor values calculated for two- and three-layer stacks could be caused by the dependency of the diffusion rate on the frequency factor. This in turn depends on geometric details of the diffusion path and the atomic density multiplied by the number of atoms that have enough energy to diffuse through the material [22]. The $\mathrm{D}_{0}$ and $\mathrm{Q}$ values are dependent on the diffusing and host species and are therefore different for every solute or solvent pair.

Many authors have used the Arrhenius plot to determine the dependency between silver diffusion and annealing temperature in thin films or bulk materials. Values ranging from 0.1 $\mathrm{eV}$ to $2.46 \mathrm{eV}$ for activation energy and from $8 \times 10^{-13} \mathrm{~m}^{2} / \mathrm{s}$ to $4 \times 10^{-6} \mathrm{~m}^{2} / \mathrm{s}$ for a frequency factor have been reposted for silver in different matrices [16, 23-26]. Activation energy, which describes the minimum energy required for diffusion to occur, varies, and depends on, the temperature and the matrix or system through which silver is diffusing. Q values obtained here are broadly similar to silver activation energy values found in other materials. The frequency factor on the other hand is between 2 to 5 orders of magnitude lower compared to those from the literature.

\section{Conclusions}

Stoichiometric $\mathrm{Si}_{3} \mathrm{~N}_{4}$ coatings were deposited by reactive magnetron sputtering. The asdeposited coatings were amorphous and remained so after annealing at $650^{\circ} \mathrm{C}$. $\mathrm{Na}$ and $\mathrm{Ag}$ diffusion rates through these layers were determined for simple $\mathrm{Ag} / \mathrm{Si}_{3} \mathrm{~N}_{4} / g$ lass stacks. $\mathrm{Na}$ diffuses more rapidly than $\mathrm{Ag}$ and the highest rates appeared to be obtained for coatings deposited under low energy conditions, but no systematic relationship between diffusion rates and deposition conditions was observed. Diffusion of Ag through 3 layer 
$\mathrm{Si}_{3} \mathrm{~N}_{4} / \mathrm{Ag} / \mathrm{Si}_{3} \mathrm{~N}_{4} /$ glass structures was also investigated. The diffusion rate followed the Arrhenius relationship; increasing with increasing annealing temperature. This suggests that even though high temperature annealing of Low-E coated glass may not cause differences in the silicon nitride film structure, a high risk of silver and sodium diffusion into constituent layers is associated with these annealing temperatures. To avoid silver diffusion during high temperature treatment a thin blocker layer would need to be deposited between the silver and neighbouring silicon nitride layers to prevent stack performance degradation due to compositional contamination. Similarly thin barrier layer would be deposited onto glass substrate to prevent sodium diffusion.

\section{Acknowledgments}

Authors would like to thank Dr. Chris Welsby, Dr. Mark Farnworth and Dr. Alex Abbott from Pilkington Technology Management Ltd. for providing XRD, XRR and TOF-SIMS analysis and Dr. Vlad Vishnyakov from the Dalton Research Institute, MMU for EDX and SEM analysis. Authors are very grateful to Professor Lindsay Greer and Dr. Zoe Barber from The University of Cambridge for their help in understanding the diffusion processes in thin films. 


\section{References}

1. I. V. Afanasyev-Charkin,L. G. Jacobsohn, R. D. Averitt, M. Nastasi, J. Vac. Sci. Technol. A, 22 (2004) 2342.

2. S. Guruvenket, J. Ghatak, P.V. Satyam, G. Mohan Rao, Thin Solid Films, 478 (2005) 256.

3. B. Li, T. Fujimoto, N. Fukumoto, K. Honda, I. Kojima, Thin Solid Films, 334 (1998) 140.

4. E. Ando, S. Suzuki, N. Aomine, M. Miyazaki, M. Tada, Vacuum, 59 (2000) 792.

5. E. Hammarberg, A. Roos, Thin Solid Films, 442 (2003) 222.

6. G. Bräuer, Surface and Coatings Technology, 112 (1999) 358.

7. A.M. Abdul-Lettif, Physica B, 388 (2007) 107.

8. A. Celik, U. Cevik, E. Bacaksiz, N. Celik, Thin Solid Films, 517 (2008) 2851.

9. I. Sugimoto, K. Yanagisawa, H. Kuwano, S. Nakano, A. Tago, J. Vac. Sci. Technol. A, 12 (1994) 2859.

10. http://gencoa.com, $20^{\text {th }}$ Sept $2011,16: 15$.

11. J. Kulczyk-Malecka, P.J. Kelly, G. West, G.C.B. Clarke, J. A. Ridealgh, Thin Solid Films, 520 (2011) 1368-1374.

12. J. Kulczyk-Malecka, Diffusion Studies in Toughenable Low-E Coatings (PhD Thesis, School of Engineering, Manchester Metropolitan University, 2012)

13. J. Crank, The Mathematics of Diffusion, $2^{\text {nd }}$ ed. (Clarendon Press, Oxford, 1975), p. 20

14. H. Mehrer, Diffusion in Solids. Fundamentals, Methods, Materials, DiffusionControlled Processes (Springer-Verlag, Berlin Heidelberg, 2007), p, 39

15. Personal communication to the authors by Dr. John Ridealgh from Pilkington Technology Management Ltd. January 2010.

16. D. Gupta, Diffusion Processes in Advanced Technological Materials (William Andrew Inc., Norwich, USA, 2005), p. 12

17. D. Gupta, P.S. Ho, Thin Solid Films, 72 (1980) 399.

18. H.P. Löbl, M. Huppertz, Thin Solid Films, 317 (1998) 153.

19. I. Kojima, B. Li, The Rigaku Journal, 16 (1999) 31.

20. B. Li, T. Fujimoto, N. Fukumoto, K. Honda, I. Kojima, Thin Solid Films, 334 (1998) 140. 
21. W. Xu, T. Fujimoto, I. Kojima, Thin Solid Films, 394 (2001) 109.

22. K.A. Jackson, Kinetic Processes. Crystal Growth, Diffusion, and Phase Transition in Materials (WILEY-VCH Verlag GmbH \& Co. KGaA, Weinheim, 2004), p. 1

23. Y.S. Lee, K.Y. Lim, Y.D. Chung, C.N. Whang, J.J. Woo, Y.P. Lee, J. Vac. Sci. Technol. A, 15 (1997) 2013.

24. L. Chen, Y. Zeng, P. Nyugen, T.L. Alford, Materials Chemistry and Physics, 76 (2002) 224.

25. L. Xiangyang, C. Huansheng, H. Wenquan, Y. Fujia, Chin. Phys. Lett., 11 (1994) 577.

26. E. Bacaksiz, O. Görür, M. Tomakin, E. Yanmaz, M. Altunbaş, Materials Letters, 61 (2007) 5239. 


\section{List of figure captions}

Figure 1: Roughness values, obtained for XRR, as a function of operating pressure for the silicon nitride samples deposited at an average target power of 150 and $300 \mathrm{~W}$.

Figure 2: SEM micrographs showing the surface morphology of silicon nitride samples 1 and 4 , respectively, deposited onto float glass substrates and post-deposition annealed at $650^{\circ} \mathrm{C}$ for 5 minutes.

Figure 3: TOF-SIMS depth profile of a 'standard' $\mathrm{Ag} / \mathrm{Si}_{3} \mathrm{~N}_{4}$ stack deposited onto float glass substrate. The profile was obtained after sample spent 24 hours at room temperature.

Figure 4: Sodium profiles collected by TOF-SIMS depth profiling analysis from as-deposited (AD) sample 6 and annealed $\mathrm{Ag} / \mathrm{Si}_{3} \mathrm{~N}_{4}$ (HT) sample 3, deposited onto float glass substrates. The approximate position of the interface between the glass and coatings is indicated, HT and AD arrows show sodium diffusion distance in sample 3 and sample 6 , respectively.

Figure 5: Arrhenius dependency between diffusion and annealing temperature obtained from selected $\mathrm{Ag} / \mathrm{Si}_{3} \mathrm{~N}_{4}$ samples annealed over the temperature range of $100-600^{\circ} \mathrm{C}$.

Figure 6: Arrhenius dependency between annealing temperature and diffusion obtained from selected $\mathrm{Si}_{3} \mathrm{~N}_{4} / \mathrm{Ag} / \mathrm{Si}_{3} \mathrm{~N}_{4}$ samples annealed over the temperature range $100-600^{\circ} \mathrm{C}$.

Figure 7: Silver distribution in $\mathrm{Si}_{3} \mathrm{~N}_{4} / \mathrm{Ag} / \mathrm{Si}_{3} \mathrm{~N}_{4}$ coatings deposited on glass and annealed over the temperature range $100-600^{\circ} \mathrm{C}$ for 5 minutes measured by TOF-SIMS depth profiling analysis. 
Table 1: Table contains silicon nitride deposition conditions, thickness and XRR density and roughness values obtained for each sample.

\begin{tabular}{|c|c|c|c|c|c|c|c|}
\hline $\begin{array}{c}\text { Sample } \\
\text { number }\end{array}$ & $\begin{array}{c}\text { Power } \\
{[\mathrm{W}]}\end{array}$ & $\begin{array}{c}\text { Pressure } \\
{[\mathrm{Pa}]}\end{array}$ & $\begin{array}{c}\mathrm{N}_{2} \text { flow } \\
{[\mathrm{SCCM}]}\end{array}$ & $\begin{array}{c}\text { Annealing } \\
\text { conditions }\end{array}$ & $\begin{array}{c}\text { Thickness } \\
{[\mathrm{nm}]}\end{array}$ & $\begin{array}{c}\text { Density } \\
{\left[\mathrm{g} / \mathrm{cm}^{3}\right]}\end{array}$ & $\begin{array}{c}\text { Roughness } \\
{[\mathrm{nm}]}\end{array}$ \\
\hline 1 & 300 & 0.3 & 10 & $650^{\circ} \mathrm{C}$ & 75.7 & 3.0 & 1.0 \\
\hline 2 & 300 & 0.5 & 9 & $650^{\circ} \mathrm{C}$ & 86.0 & 3.0 & 1.2 \\
\hline 3 & 300 & 0.9 & 9 & $650^{\circ} \mathrm{C}$ & 86.7 & 2.9 & 3.1 \\
\hline 4 & 150 & 0.3 & 9 & $650^{\circ} \mathrm{C}$ & 76.8 & 3.0 & 1.9 \\
\hline 5 & 150 & 0.5 & 11 & $650^{\circ} \mathrm{C}$ & 70.8 & 2.7 & 2.1 \\
\hline 6 & 300 & 0.9 & 9 & Not annealed & 85.6 & 2.9 & 2.8 \\
\hline
\end{tabular}


Table 2: Silver diffusion coefficient values obtained for $\mathrm{Ag} / \mathrm{Si}_{3} \mathrm{~N}_{4}$ samples annealed at 100 , 250,400 and $600^{\circ} \mathrm{C}$ for 5 minutes.

\begin{tabular}{|c|c|}
\hline Annealing Temperature $\left[{ }^{\circ} \mathrm{C}\right]$ & $\mathrm{D}_{\mathrm{Ag}}\left[\mathrm{m}^{2} / \mathrm{s}\right]$ \\
\hline 100 & $3.64 \times 10^{-21}$ \\
\hline 250 & $1.00 \times 10^{-20}$ \\
\hline 400 & $1.09 \times 10^{-18}$ \\
\hline 600 & $2.45 \times 10^{-18}$ \\
\hline
\end{tabular}


Table 3: Silver diffusion coefficient values obtained for $\mathrm{Si}_{3} \mathrm{~N}_{4} / \mathrm{Ag} / \mathrm{Si}_{3} \mathrm{~N}_{4}$ samples annealed at different temperatures.

\begin{tabular}{|c|c|}
\hline Annealing Temperatures $\left[{ }^{\circ} \mathrm{C}\right]$ & $\mathrm{D}_{\mathrm{Ag}}\left[\mathrm{m}^{2} / \mathrm{s}\right]$ \\
\hline 100 & $1.00 \times 10^{-21}$ \\
\hline 200 & $4.25 \times 10^{-21}$ \\
\hline 250 & $4.75 \times 10^{-21}$ \\
\hline 300 & $1.75 \times 10^{-20}$ \\
\hline 400 & $6.65 \times 10^{-20}$ \\
\hline 500 & $1.05 \times 10^{-19}$ \\
\hline 600 & $7.65 \times 10^{-19}$ \\
\hline
\end{tabular}




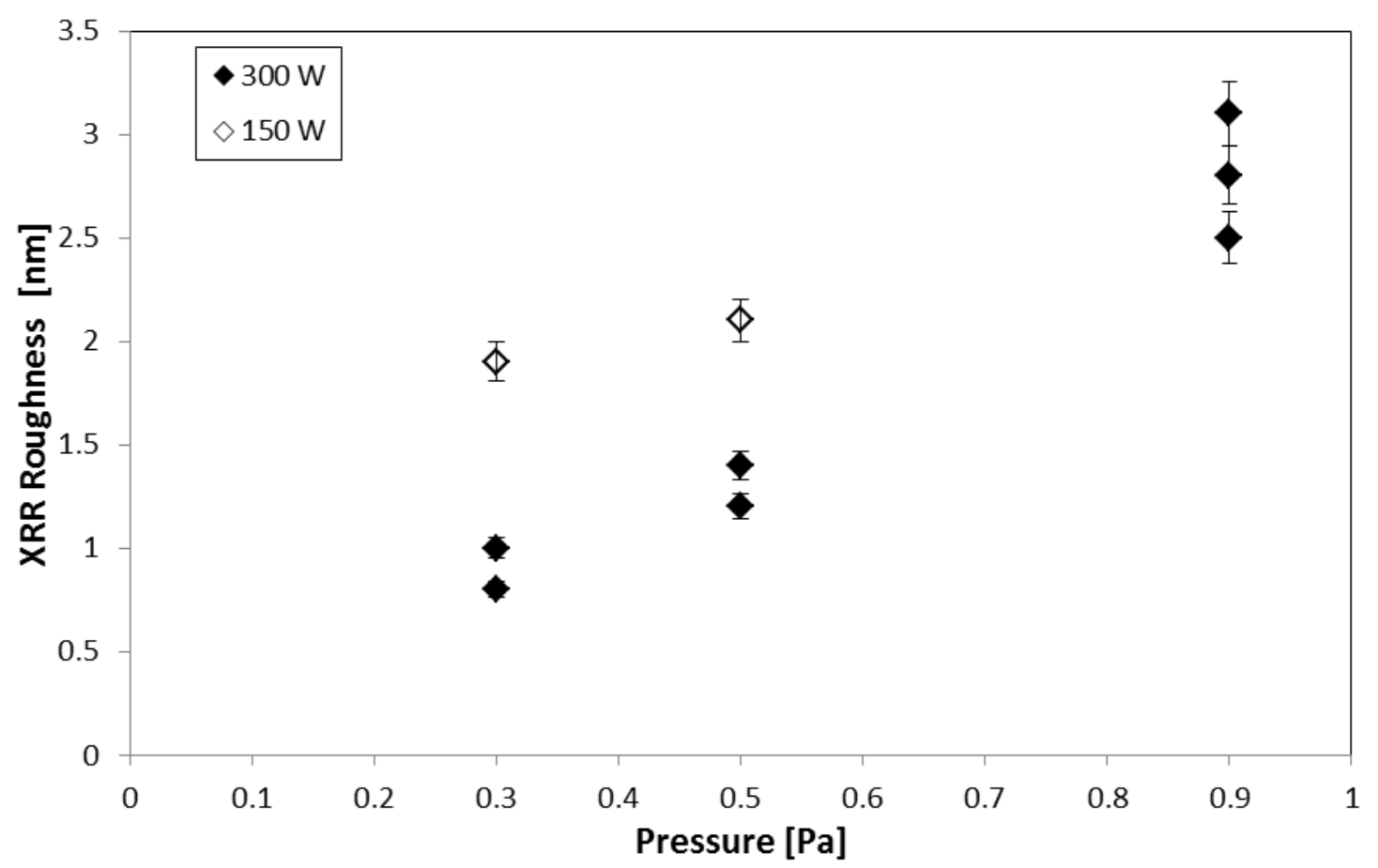

Figure 1 

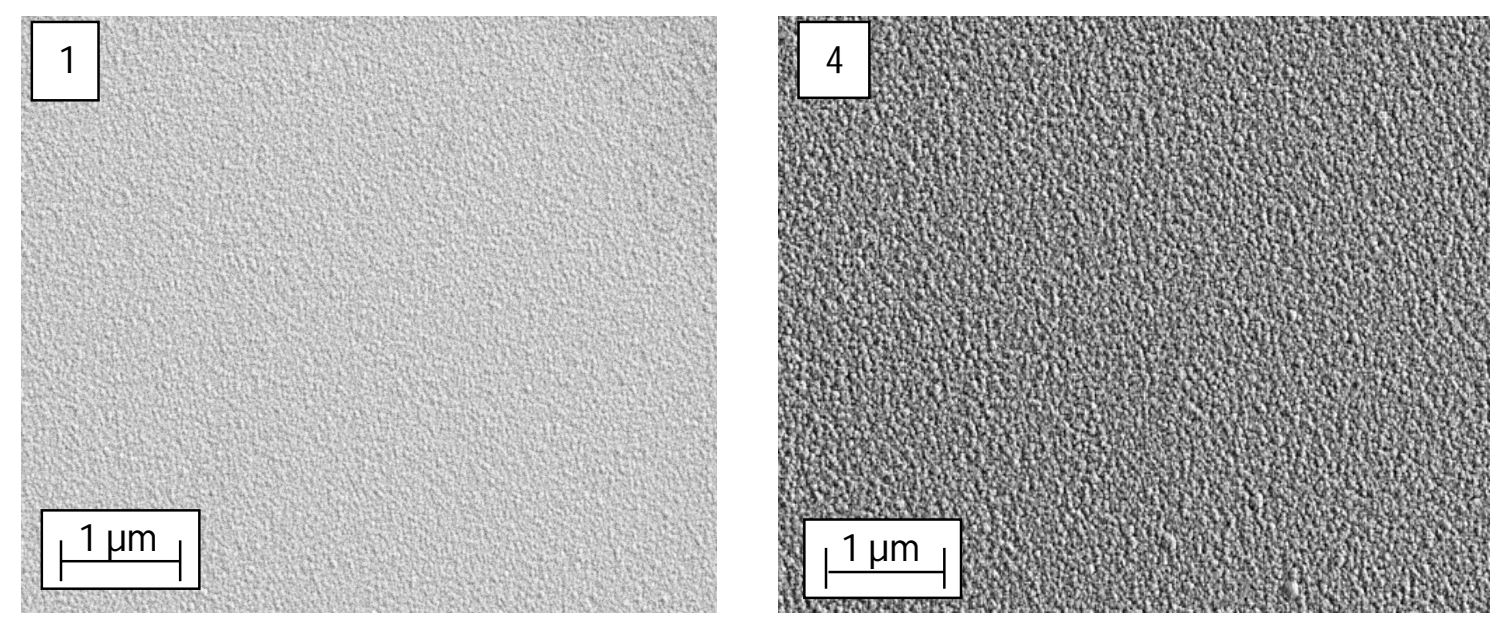

Figure 2 


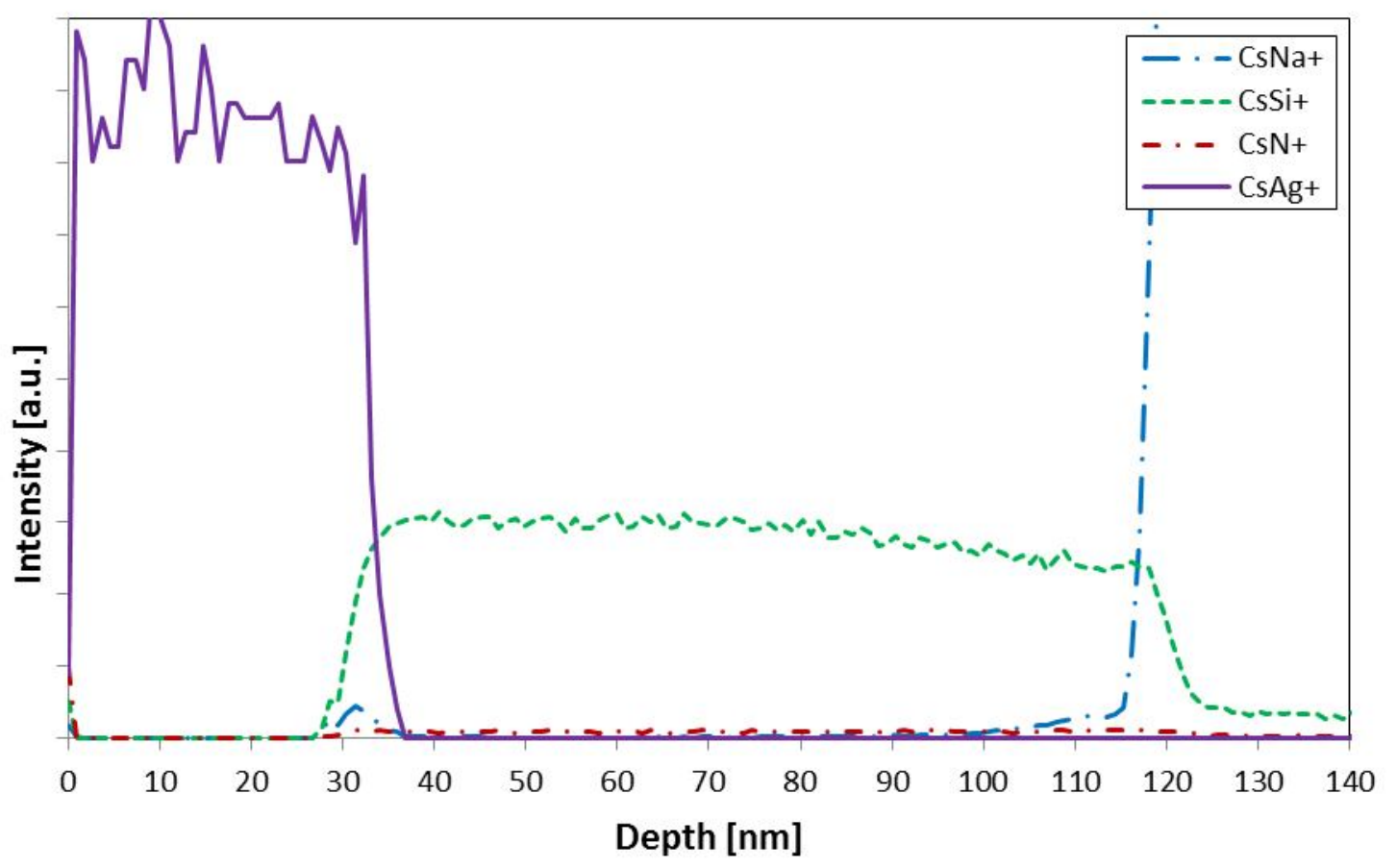

Figure 3 


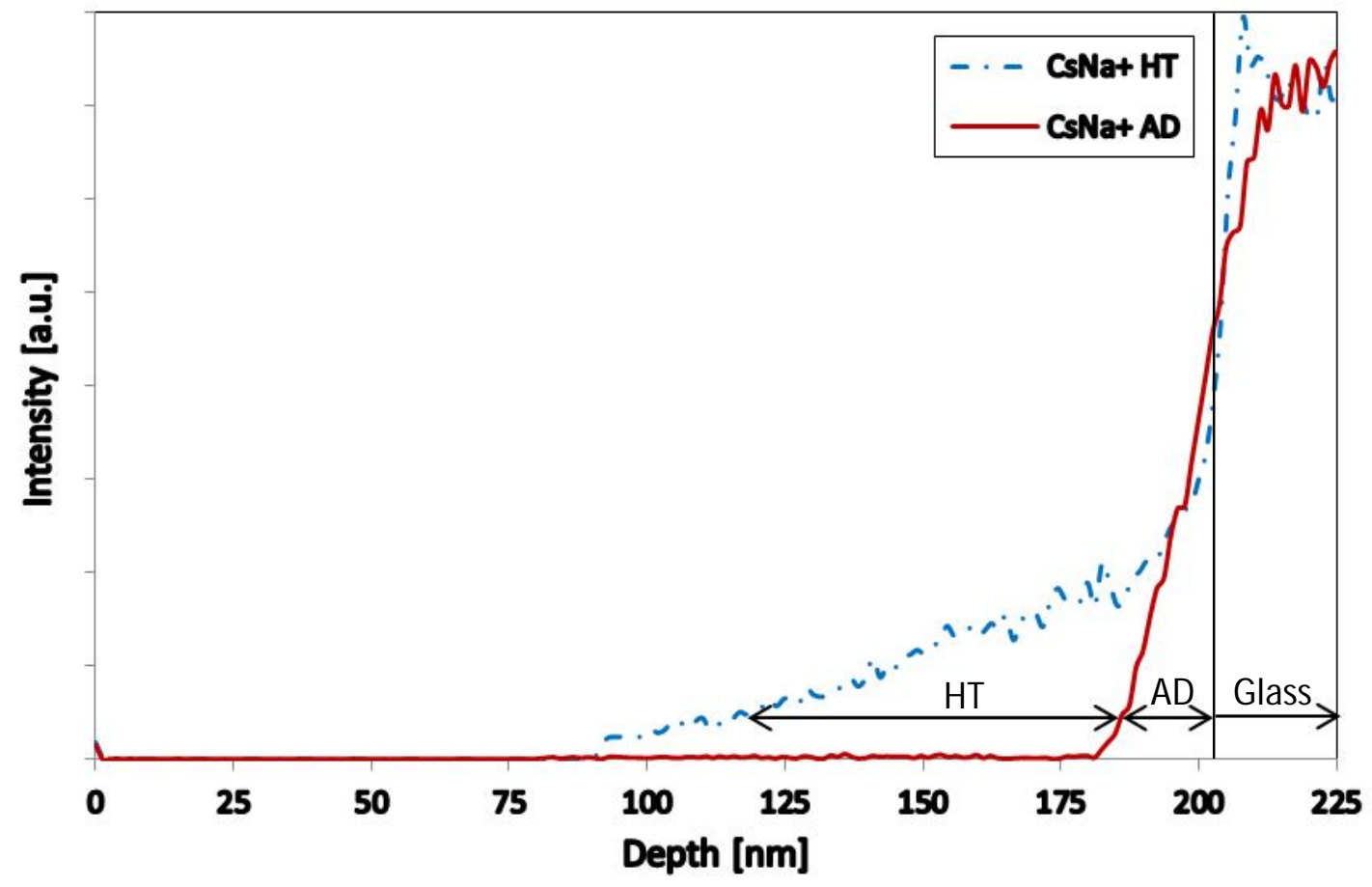

Figure 4 


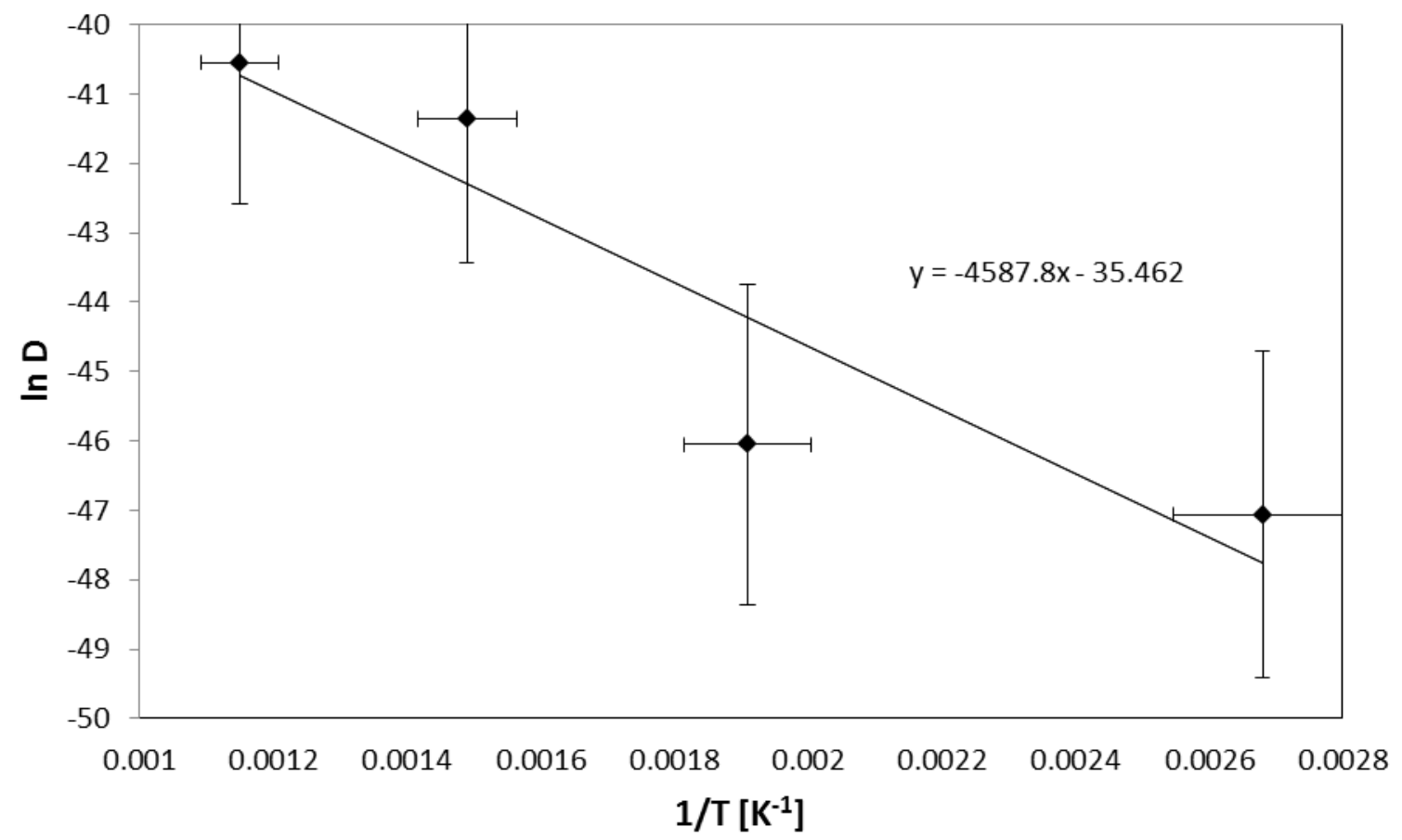

Figure 5 


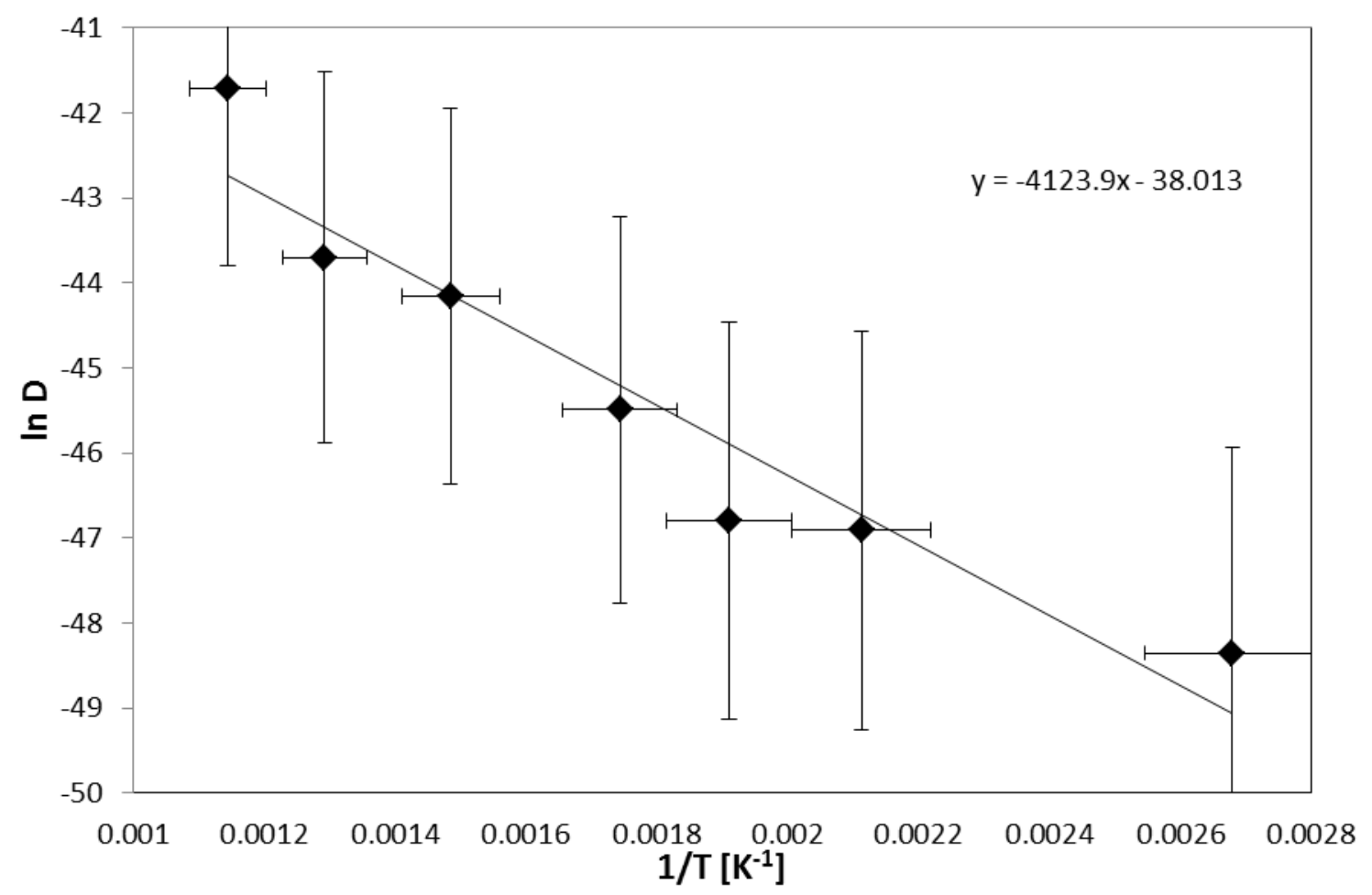

Figure 6 


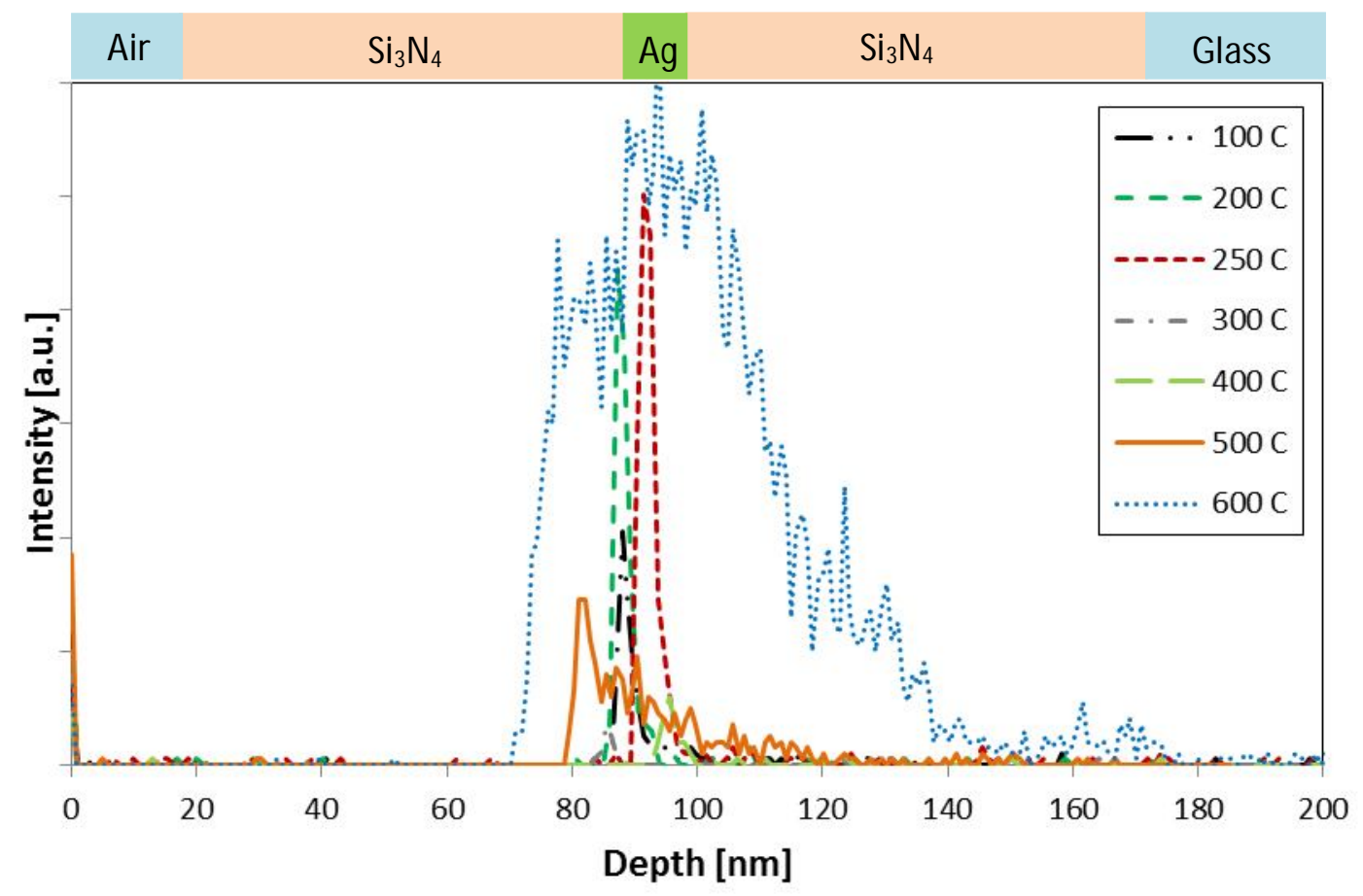

Figure 7 